


\title{
PLANOS URBANOS E CENTRO HISTÓRICO DE BELÉM'
}

\author{
URBAN PLANS ANDTHE HISTORIC CENTRE OF BELEM
}

PLANES URBANESY EL CENTRO HISTÓRICO DE BELÉM

\author{
Helena Lúcia ZaguryTourinho² \\ Davina Bernadete Oliveira Lima ${ }^{3}$
}

\section{Resumo}

Os papéis e funções dos centros das cidades brasileiras sofreram muitas mudanças nas últimas décadas. O artigo investiga "se" e "como" os planos urbanos de Belém apreenderam tais mudanças. Mostra que, apesar de estabelecer diretrizes e instrumentos para a preservação do patrimônio construído, os planos desenvolvidos para essa cidade não aprofundaram a discussão sobre os papéis e funções do Centro Histórico de Belém, tendo pouca de suas ações previstas sido implementadas.

Palavras-chave: Centro histórico. Planos urbanos. Centro Histórico de Belém.

\begin{abstract}
The rolls and functions of Brazilian's cities centers have significantly changed over the last decades. This paper examines "if" and "how" the Belem's urban plans have incorporated such changes. Finally, it shows that, despite those urban plans have established guidelines and instruments for built heritage preservation, they didn't profoundly discussed the rolls and functions of the Historical Center of Belem, as result, few of its planned actions have been implemented.
\end{abstract}

Keywords: Historical City Center. Urban plans. Historical City Center of Belem.

\section{Resumen}

Las funciones de los centros de las ciudades han experimentado muchos cambios en las últimas décadas. El artículo investiga "sí" y "cómo" los planes urbanísticos de Belém aprehendieron tales cambios. Demuestra que, aunque tengan establecido directrices e instrumentos para la preservación del patrimonio construido, los planes no avanzaron en la discusión acerca de los papeles y de las funciones de lo del Centro Histórico de Belém, tiendo poco de las acciones previamente planeadas efectivamente implementadas.

Palabras clave: Centro histórico. Planes urbanos. Centro Histórico de Belém. 


\section{Introdução}

O processo de formação dos núcleos urbanos se dá baseado nas relações dialéticas que os diversos agentes sociais, econômicos e políticos estabelecem entre si e com o espaço. Essas relações, desenvolvidas ao longo do tempo, configuram os espaços construídos das cidades, entre os quais o centro, local de grande movimentação econômica, social, política, religiosa e cultural.

No Brasil, até a década de 1970, o centro era o espaço mais importante da cidade. Para ele convergiam os principais investimentos, assim como as pessoas com seus desejos e necessidades de consumir, já que lá estava a oferta principal de produtos e serviços. Por sua localização estratégica, o centro era o ponto mais acessível da urbe. Nesse espaço, concentravam-se equipamentos urbanos de uso coletivo, terminais de transporte, templos religiosos, locais de diversão, sedes dos poderes institucionais e o maior aglomerado de comércio e serviços da cidade. Todos esses fatores imprimiam ao centro características de principal centralidade urbana (TOURINHO, 2007; VILLAÇA, 2001).

Após meados da década de 1970 e sobretudo a partir do final da década de 1980, esse quadro começou a ser alterado. O avanço do processo de descentralização das atividades econômicas, a formação de novas centralidades urbanas em outras áreas da cidade (por exemplo: instalação de shopping centers fora do centro tradicional), o deslocamento das residências das camadas de maiores rendas para outras áreas da cidade, inclusive para condomínios localizados em áreas periféricas, promoveram o rompimento da estrutura intraurbana mononucleada, do tipo centro-periferia, e afetaram sobremaneira as funções e a ocupação do centro, sobretudo na sua área mais antiga denominada "centro histórico". Nesta se desencadeou um processo de degradação do ambiente construído com profundas repercussões para a preservação do patrimônio cultural.

Este artigo investiga se os planos diretores que trataram do ordenamento territorial de Belém apreenderam essas mudanças e como propuseram nelas intervir. Para isso, primeiramente, conceitua "centro urbano" e "centro histórico", apontando os principais papéis desempenhados por eles ao longo do tempo. Na sequência, analisa o processo de formação e instituição do Centro Histórico de Belém (CHB) e, finalmente, apresenta e discute o centro histórico nos principais planos compreensivos desenvolvidos para Belém: o Plano de Desenvolvimento da Grande Belém (PDGB); o Plano de Estruturação Metropolitana (PEM); o Plano Diretor do Município de Belém de 1993; e o Plano Diretor do Município de Belém de 2008.

\section{Centro urbano e centralidade}

Conforme Villaça (2012, p. 91), o centro é "o mais importante elemento da estrutura urbana; é o único que existe em todas as cidades de todos os tamanhos e de qualquer período histó- 
rico". É, portanto, o elemento fundamental na constituição da cidade, aquele que agrega e estrutura todos os demais.

Resultado da correlação de forças estabelecida entre os diversos agentes que atuam no espaço, o centro emergiu, historicamente, em razão da necessidade de evitar, minimizar ou apenas controlar os gastos com deslocamentos indesejados, mas obrigatórios (VILLAÇA, 2001). A disputa pelo controle do tempo e da energia despendidos nos deslocamentos humanos resultou, segundo Villaça (2012), na aglomeração espacial de instituições comandadas pelas elites econômicas, religiosas, militares e políticas das sociedades. Essas elites, por promoverem a dinâmica do Centro, podem valorizá-lo ou, por sua conveniência, relegá-lo ao abandono e ao esvaziamento, o que ocorreu quando esse tipo de arranjo espacial deixou de atender às suas necessidades, sobretudo as econômicas.

Ocorre que centro da cidade é fundamental para a coordenação das atividades urbanas; ele proporciona uma identificação simbólica e ordenada das atividades, condição necessária à comunicação entre os atores sociais (LEFEBVRE, 2002).

Nas cidades pré-capitalistas, o centro concentrava, fundamentalmente, as atividades de poder e de comando religioso e político. No capitalismo, as atividades de comércio de mercadorias e de prestação de serviços assumem papel relevante, passando a imprimir, ao centro, novas características de organização espacial.

Para Villaça (2012, p. 110), a cidade capitalista será a primeira da história "cujo centro não exaltará nem a Deus e nem o Estado". Em vez disso, nela, o centro é "dominado pela atividade privada de comércio e serviço, pela propriedade privada da terra urbana e pelo mercado imobiliário, [...] por um sistema viário uniforme e pelo intenso uso do solo".

No início, a centralidade urbana se definia por um conjunto de qualidades conferidas ao centro historicamente construído, sendo atributo exclusivo deste. Nas décadas recentes, como resultado dos processos de expansão do centro tradicional e de formação de novas centralidades urbanas, o centro original deixou de ser a referência exclusiva de centralidade urbana.

Não obstante, a centralidade do centro não é apenas operativa ou funcional, é também uma centralidade representativa, que simboliza a qualidade dos fenômenos que lá acontecem (TOURINHO, 2007).

Lefebvre (1991) mostra que, na cidade capitalista, marcada pelo consumo e pela produção industrial, o centro apresenta um duplo caráter: além de lugar de consumo, converte-se em espaço de consumo do lugar. Assim, no âmbito do processo de globalização da economia, a parte do centro urbano mais antiga, agora denominada de centro histórico (como se o restante do centro não o fosse), assume relevância particular, convertendo-se em espaços que necessitam ser preservados.

É na gênese da primeira centralidade urbana e no seu desenvolvimento, portanto, que emergiu e se forjou o chamado centro histórico. 


\section{O centro histórico}

O centro histórico é, normalmente, a parte do centro tradicional caracterizada por ser o local mais antigo da cidade; é o centro funcional inicial, ou seja, o espaço que, ao longo do tempo, polarizou importantes funções sociais, econômicas, habitacionais e institucionais.

As áreas da cidade hoje consideradas centro histórico, no passado, abrigavam as atividades mais importantes do núcleo urbano, apresentando centralidades geográfica, social e econômica. Em razão de sua acessibilidade, para essa área convergiam os principais fluxos de mercadorias e pessoas, razão pela qual apresentava uma posição geográfica estratégica na cidade. Sua relevância econômica se justificava por ser o local onde estavam estabelecidos os comércios mais importantes, as sedes das empresas e da Administração Pública e, não raras vezes, os portos e terminais de fluxos interurbanos. Do ponto de vista social, era o principal local de encontros, de lazer, de intercâmbio de informações, de manifestações religiosas, cívicas e políticas (SEBASTIÃO, 2010).

Hoje, além de ainda ser o locus de concentração de várias atividades econômicas, sociais, políticas e culturais, o centro antigo é importante legado histórico das sociedades já que abriga uma sucessão de testemunhos de várias épocas passadas, fornecendo "a dimensão temporal com a sequência dos fatos que estruturam as identidades" locais (SALGUEIRO, 2005 citado por SEBASTIÃO, 2010, p. 20).

Rémy e Voyé (2004 citados por SEBASTIÃO, 2010, p. 20) consideram o centro histórico como "o lugar simbólico por excelência, o da história e da memória coletiva". Cavém (2007 citado por SEBASTIÃO, 2010, p. 20) ressalta que "o elemento mais marcante de um centro histórico, na atualidade, é a sua imagem simbólica", pois esta permanece, mesmo quando o centro perde sua atratividade econômica.

A partir do século passado, os centros históricos de muitas cidades começaram a passar por profundos e acelerados processos de degradação física e ambiental, decorrente da migração da população de maior renda, que lá morava, para outras áreas da cidade e, com elas, das atividades mais sofisticadas de comércio e serviços (TOURINHO, 2007; VILLAÇA, 2012).

Para conter e contrarrestar esse movimento de esvaziamento econômico e de degradação física, garantindo a preservação do patrimônio arquitetônico, artístico e cultural, vários documentos internacionais e nacionais foram produzidos, dentre os quais se destacam as cartas patrimoniais, as legislações urbanísticas de preservação do patrimônio.

Considerado o primeiro ato normativo dedicado exclusivamente ao patrimônio, a Carta de Atenas sobre o Restauro dos Monumentos, de 1931, enfatizou a proteção dos monumentos ameaçados pela interferência visual causada pela construção de imóveis no entorno, de publicidade e de postes e fiação; e poluição consequente da instalação de atividades inadequadas na vizinhança (CARTA..., 1999). 
Mais tarde, a Carta de Atenas, de 1933, reiterou a importância do patrimônio ao propor que os valores arquitetônicos deveriam ser salvaguardados (edifícios isolados ou conjuntos urbanos) por serem testemunhos preciosos do passado, "pelo seu valor histórico e sentimental" (BRASIL, 2000a, p. 25). Mas, ao mesmo tempo, admitiu a sua demolição ao afirmar que "em nenhum caso, o culto do pitoresco e da história deve ter primazia sobre a salubridade da moradia da qual dependem tão estritamente o bem-estar e a saúde moral do indivíduo" (BRASIL, 2000a, p. 26).

Em 1964, a Carta de Veneza (UNESCO, 1999b) versou sobre a conservação e o restauro de monumentos. Essa carta estendeu a conservação aos sítios históricos, destacando as necessidades de permanente manutenção, incentivo à utilidade social e à adaptação funcional (SEBASTIÃO, 2010).

Na mesma linha, a Carta de Nairóbi, de 1976, definiu os conjuntos históricos mostrando a relevância desses espaços para a humanidade. Esse documento estabeleceu, como um de seus princípios gerais, que "os conjuntos históricos ou tradicionais e sua ambiência constituem um patrimônio universal insubstituível" (UNESCO, 1999a, p. 190).

A Carta Internacional para a Salvaguarda das Cidades Históricas (Carta de Washington), de 1986 (ICOMOS, 1999), reforçou a importância dos centros históricos, argumentando que estes expressam os valores próprios das civilizações urbanas tradicionais devendo, por isso, ser preservado "todo o conjunto de elementos materiais e espirituais que contribuíssem para a definição da imagem do centro histórico" (ANDRADE, 1999 citado por SEBASTIÃO, 2010, p. 31).

A Carta de Washington apresentou o conceito de "salvaguarda das cidades históricas", relacionando-o com as medidas necessárias à proteção, conservação e restauro, bem como ao desenvolvimento e adaptação harmoniosa à vida contemporânea. A salvaguarda foi entendida como "parte essencial de uma política coerente de desenvolvimento econômico e social, e ser considerada no planejamento físico territorial e nos planos urbanos em todos os seus níveis" (ICOMOS, 1999, p. 228). O mesmo documento afirma também que a "conservação das cidades e bairros históricos implica a manutenção permanente do parque edificado" (ICOMOS, 1999, p. 230).

No Brasil, merece destaque a Carta de Petrópolis, resultante do $1^{\circ}$ Seminário Brasileiro para a Preservação e Revitalização de Centros Históricos, realizado em 1987 (BRASIL, 2000b). Nesse documento, foi conceituado "sítio histórico urbano" (SHU) e apontada a importância primordial da sua manutenção e potencialização para a expressão e consolidação da cidadania.

Para essa carta: a moradia é a função primordial do espaço edificado nos centros históricos; a ação integrada dos órgãos federais, estaduais e municipais, assim como a participação da comunidade interessada nas decisões de planejamento são fundamentais; e a proteção legal do SHU deve ser feita por meio de instrumentos urbanísticos, jurídicos e fiscais, dentre outros (BRASIL, 2000b). 
Concomitantemente à elaboração das primeiras cartas patrimoniais, iniciou-se no Brasil o processo de instrumentalização legal da proteção do patrimônio, sob a influência do Movimento Modernista, representado pelos intelectuais do IPHAN, que, segundo Villaschi (2008, p. 27), "tinham o projeto de preservação do Patrimônio Cultural como o mais importante instrumento de transformação da realidade brasileira e de construção de uma nação globalizante e inclusiva".

Nesse contexto, foi publicado o Decreto-Lei n. ${ }^{\circ} 25$, de 30 de novembro de 1937, que instituiu o tombamento como principal instrumento de proteção do patrimônio, capaz de contribuir para a preservação de bens móveis e imóveis (BRASIL, 1937).

Ressalte-se que, se por um lado, o tombamento ainda é um instrumento importantíssimo para a preservação do bem histórico, por outro, quando desacompanhado de outras políticas e ações que estimulem a manutenção da vitalidade e a ocupação dos sítios com usos sustentáveis, podem contribuir para acelerar o processo de degradação física e socioeconômica desses espaços.

A responsabilidade pela preservação dos sítios históricos tombados acabou ficando, majoritariamente, no âmbito do município, que detém, entre outras, a competência constitucional de promover o planejamento urbano e regulamentar o uso e a ocupação do solo urbano, o que o faz mediante seus planos diretores e legislação urbanística.

Os centros históricos, pela relevância que têm, portanto, de uma forma ou de outra, sempre estão presentes nos planos diretores, como ocorre no caso de Belém.

\section{Contextualização do Centro Histórico de Belém (CHB)}

Parte integrante da principal concentração de comércios e serviços do Município e da Região Metropolitana de Belém, o CHB situa-se na extremidade sudoeste da área continental do Município, no pontal delimitado pelo rio Guamá e pela baía do Guajará, próximo da foz do rio Pará, e pela Avenida Assis de Vasconcelos, Rua Gama Abreu e Avenida Almirante Tamandaré. Essa posição geográfica era estratégica para a economia regional, o que contribuiu para que se tornasse o principal entreposto comercial da Região Amazônica (FIG. 1).

Entre meados do século XIX e o início do século XX, como resultado do desenvolvimento econômico proporcionado pela exploração da borracha vegetal, a cidade foi objeto de transformações urbanísticas, paisagísticas e arquitetônicas. Na época, uma avalanche de obras e inovações urbanas foram introduzidas, sob a administração do intendente Antônio Lemos, grande parte das quais localizadas na área que hoje constitui seu centro histórico, como a pavimentação de vias com paralelepípedos de granito procedente de Portugal, a criação e o paisagismo de praças públicas, a substituição dos beirais das edificações por platibandas e construção de vários prédios, como os do Arquivo e Biblioteca Públicos, o Teatro da Paz, etc. (SARGES, 2002). 


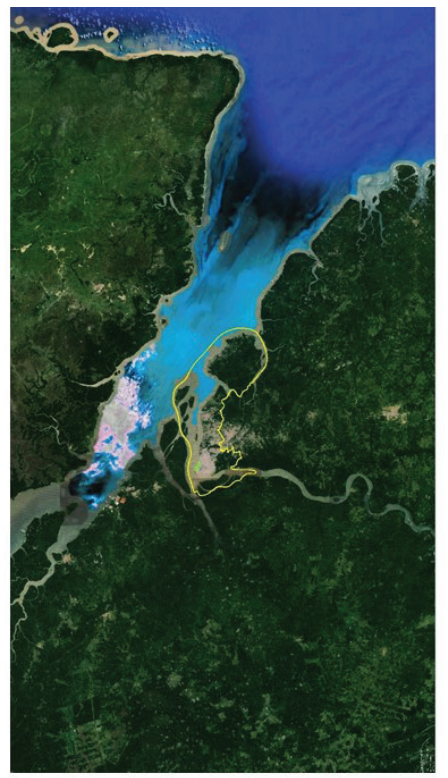

$\square$ Limite do Municipio de Belém

Com o declínio do ciclo econômico da borracha, os investimentos públicos e privados no centro foram desacelerados, e o movimento nos portos do $\mathrm{CHB}$ se tornou restrito, limitando-se praticamente aos fluxos regionais de produtos e passageiros, estes procedentes, sobretudo, de cidades e povoados ribeirinhos da Amazônia.

Em fins da década de 1960, Penteado (1968) já identificava a decadência física do bairro da Cidade Velha e, junto com o aumento da atividade comercial e a redução do uso habitacional no Bairro da Campina, a ocorrência de processo de verticalização em torno da Avenida Presidente Vargas. Ao longo e em torno desse eixo se localizaram algumas atividades terciárias, sobretudo as voltadas para as camadas de maior renda, como cinemas, bancos, agência central de correios e telégrafos, lojas sofisticadas, prédios de escritórios e consultórios mais modernos.

É de se realçar que, até a década de 1960, a legislação urbanística belenense não apresentou preocupação explícita com a preservação do Centro Histórico. Na década de 1950, inclusive, incentivou a verticalização, o que colaborou para a demolição de edificações relevantes e para emergência de um eixo verticalizado anteriormente citado.

O deslocamento das residências das camadas mais abastadas para áreas localizadas no entorno do Centro Histórico, também foi observado por Penteado (1968), que identificou, nos bairros de Nazaré e Batista Campos, a presença de palacetes e prédios verticalizados.

O processo de descentralização e o movimento de saída das camadas de maior renda para outras áreas da cidade se intensificaram nas décadas seguintes, e geraram a formação de alguns subcentros importantes, como os de Icoaraci e do Entroncamento e, mais recentemente, os localizados ao longo de corredores de transporte, como a Avenida Augusto Montenegro.

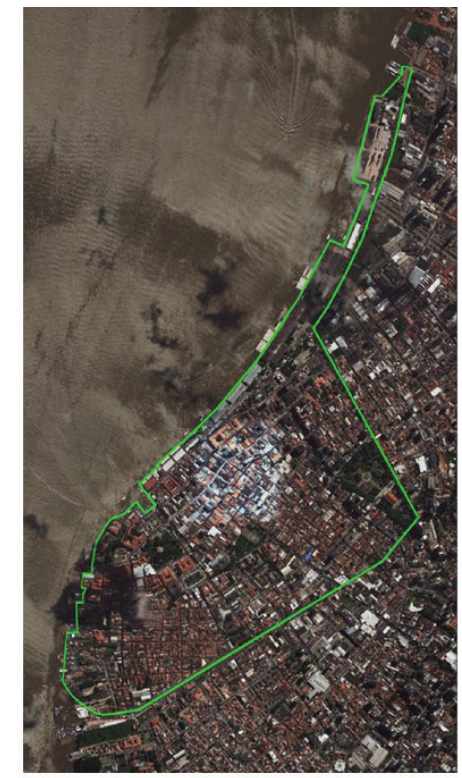

Limite do $\mathrm{CHB}$

Figura 1 • Localização do Centro Histórico de Belém

Fonte: Elaborado por Davina Lima e Edilson Rosa, com base em Google Earth (2015), Belém (1994) e Pará (1993).

Cadernos de Arquitetura e Urbanismo, v.22, n.30, 2º sem. 2015 
A expansão da malha urbana, a implantação de conjuntos habitacionais populares, de shopping centers e de condomínios residenciais fechados para alta e média renda, cada vez mais distantes do $\mathrm{CHB}$, assim como os crescentes problemas de acessibilidade intraurbana colaboraram para transformações nas funções desempenhadas pelo Centro Histórico belenense, fazendo com que suas atividades terciárias fossem, progressivamente, voltando-se para o atendimento de camadas populares.

As mudanças no padrão econômico das atividades e a saída dos moradores mais abastados refletiram, de forma marcante, nas condições físicas do CHB, resultando no abandono, na descaracterização e na subutilização de várias edificações, além do esvaziamento do uso habitacional em algumas áreas.

A ociosidade imobiliária pode ser mais bem percebida a partir dos dados do Censo Demográfico, que registrou, em 2010, 982 domicílios não ocupados nos bairros da Cidade Velha e Campina que integram o CHB (MERCÊS; TOURINHO; LÔBO, 2014).

Ressalte-se que vem colaborando para isso o fato de as características arquitetônicas e funcionais dos prédios não atenderem mais às necessidades espaciais demandadas pelos novos padrões de morar e de desenvolver atividades de comércio e serviços, tais como as de espaços amplos para estacionamentos e instalações de refrigeração. Além disso, são tidos como entraves consideráveis os limites rígidos à adaptação dos imóveis, impostos pelo tombamento, e os elevados custos de recuperação e manutenção dos prédios antigos.

Vale ressaltar que, embora, em muitas cidades, a migração das atividades sofisticadas das camadas de maior renda para outras áreas da cidade tenha levado à decadência econômica do Centro Histórico, no caso de Belém, isso não se verificou, pelo menos até o presente. Segundo dados da pesquisa "Funcionamento do mercado imobiliário em centros históricos das cidades brasileiras", em 1997, quando o CHB já enfrentava problemas de conservação, havia 1.652 lotes com uso exclusivo habitacional; em 2013, essa quantidade era de 1.518 unidades.

$\mathrm{O}$ CHB permanece com muita vitalidade, abrigando atividades administrativas importantes (sede da Prefeitura, da Assembleia Legislativa, do Fórum, etc.); muitos estabelecimentos de comércio e serviços, sobretudo aqueles voltados para o mercado popular; um expressivo contingente de usos habitacionais, ocupado especialmente por camadas de rendas média e baixa que conseguem pagar pela localização central; e catalisando significativos fluxos regionais de pessoas e de mercadorias.

Contribui para isso, de certo modo, algumas intervenções que vêm sendo realizadas na área, desde a década de 1970, pela Prefeitura Municipal e pelos governos estadual e federal, sistematizadas na FIG. 2. Dentre essas ações se destacam as requalificações do Ver-o-Peso ${ }^{4}$ (FIG. 3) pela Prefeitura Municipal de Belém, a implantação do Complexo de Lazer da Estação das $\operatorname{Docas}^{5}$ (FIG. 4) e do Projeto Feliz Lusitânia ${ }^{6}$ (FIG. 5) pelo Governo do Estado do Pará, estas duas últimas inseridas em uma política de estímulo à atividade turística no $\mathrm{CHB}$.
4. O Ver-o-Peso está localizado às margens da baía do Guajará. O complexo é composto por mercados e feiras onde são vendidos frutos, ervas, pescado, carne e uma gama de outros produtos procedentes do interior do Estado e transportados, principalmente, por via fluvial. Ponto turístico e cultural da cidade, o Ver-o-Peso é considerado a maior feira ao ar livre da América Latina, sendo um dos mercados públicos mais antigos do Brasil.

5. Inaugurada em maio de 2000 , a Estação das Docas é um complexo turístico e cultural que congrega gastronomia, cultura e eventos em cerca de 500 metros de orla fluvial, onde outrora se localizava o antigo porto de Belém. Para sua implantação, foi realizado cuidadoso trabalho de restauração de três galpões de ferro inglês (da segunda metade do século $X(X)$, guindastes externos fabricados nos Estados Unidos, no começo do século $X X$, e máquina a vapor, de meados de 1800, que fornecia energia para os equipamentos do porto. Integram também o conjunto as ruínas do Forte de São Pedro Nolasco, onde foi construído um anfiteatro. Esse forte foi construído em 1665, para a defesa da orla, e destruído após o Movimento da Cabanagem, em 1825

(A ESTAÇÃO, 2015)

6. Desenvolvido por meio de parceria entre governo do Estado, governo federal, Instituto do Patrimônio Histórico e Artístico Nacional e empresas privadas, o Feliz Lusitânia se localiza no sítio de ocupação mais antiga da cidade, onde estão localizados o Forte do Castelo, a Praça da Sé, as igrejas da Sé e de Santo Alexandre, o Palácio Episcopal e a Ladeira do Castelo, antiga Rua do Seminário. O projeto restaurou, entre outros, a Igreja de Santo Alexandre; o Palácio Episcopal, concluído em 1719, onde passou a funcionar o Museu de Arte Sacra do Pará; o Forte do Castelo; a Praça Frei Caetano Brandão; o Palacete das Onze Janelas, erguido no século XVIII; e a Catedral Metropolitana, cuja construção foi concluída em 1782, por Antônio Landi.

Cadernos de Arquitetura e Uthanismo, v.22, п.30, $1^{0}$ sem. 2015 


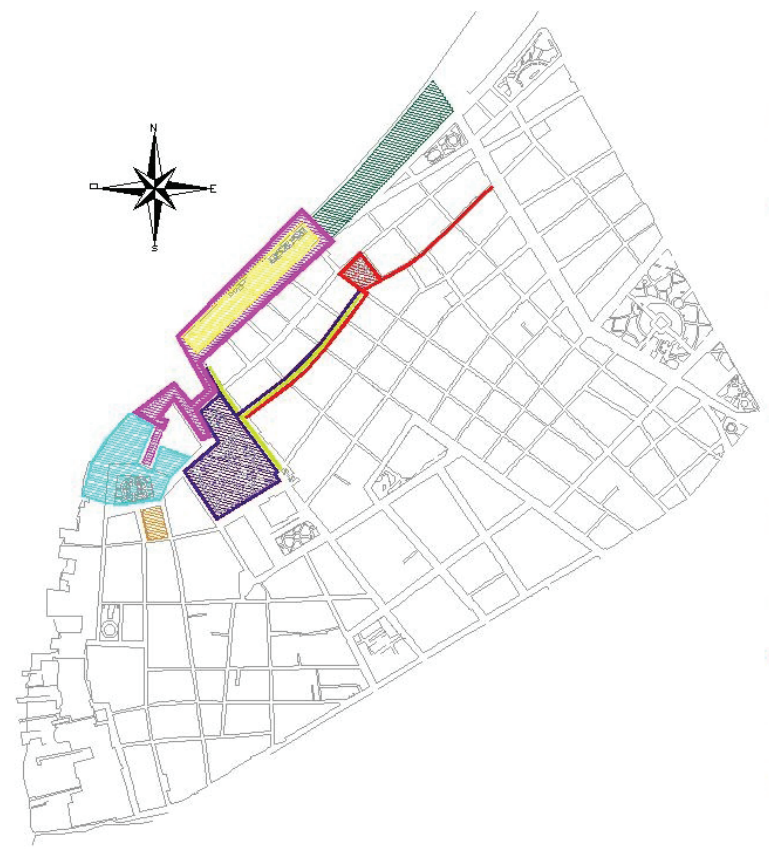

LEGENDA:

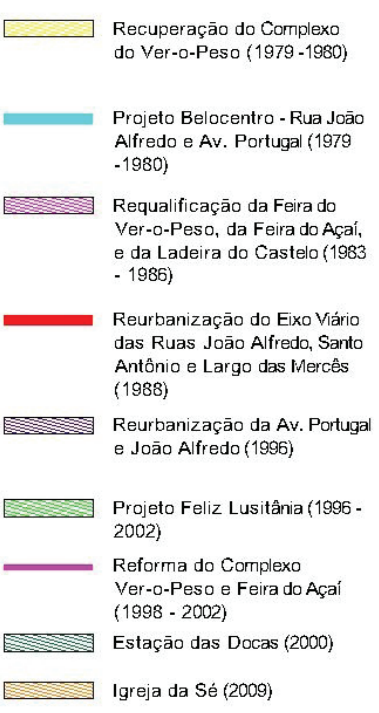

Figura 2 • Intervenções no Centro Histórico de Belém

Fonte: Elaborado por Davina Lima e Rafaela Viana, com base em COHAB (2009) e Ver-o-Site (2015).

Figura 3 • Complexo do Ver-o-Peso Fonte: WIKILICIAS (2014).

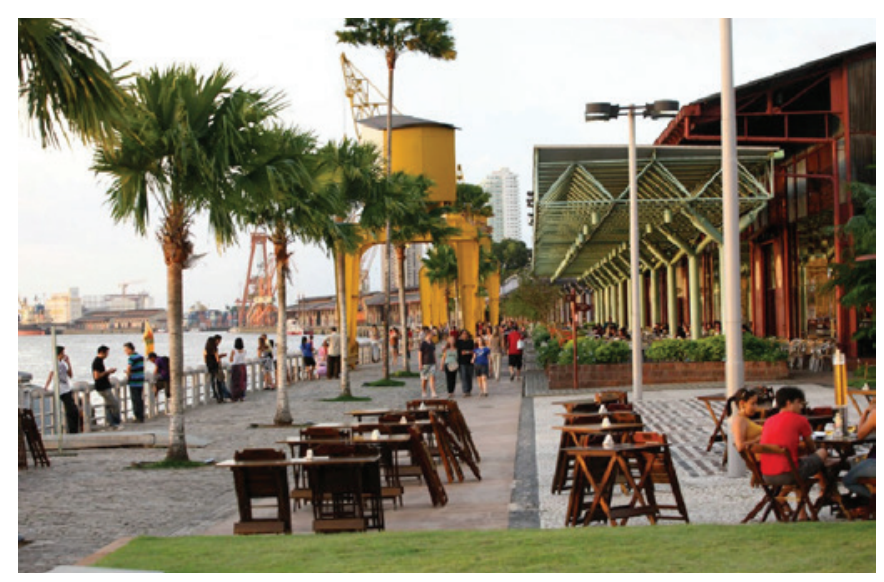

Figura 4 • Complexo Estação das Docas Fonte: PARAONLINE (2013).

Cadernos de Arquitetura e Urbanismo, v.22, n.30, $2^{0}$ sem. 2015 


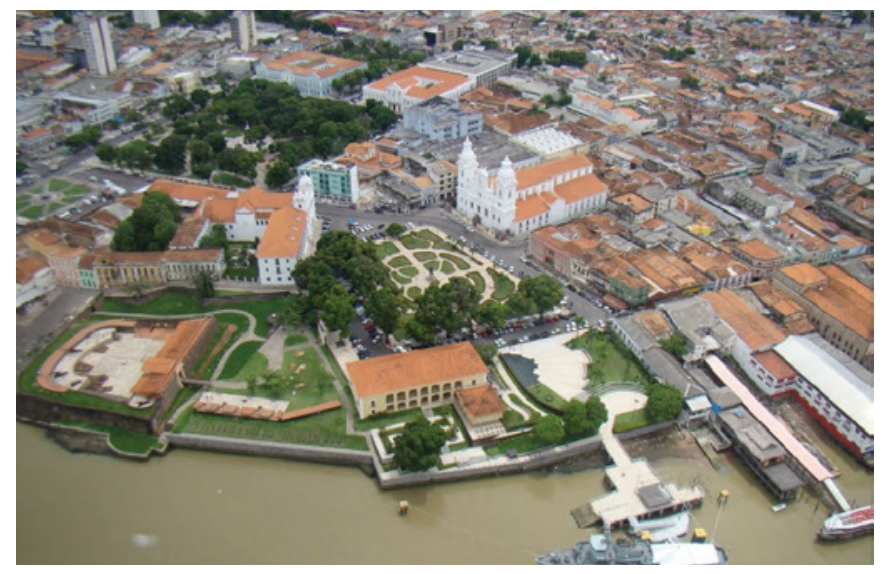

Essas intervenções, embora classificadas, por alguns, como projetos classistas, vinculados a uma estratégia excludente de gentrificação do espaço central, até o presente, não foram capazes de alterar, de forma substancial, o perfil socioeconômico das atividades e dos moradores do CHB.

A partir da década de 1960, com a instituição do tombamento em Belém - em 1964, foi tombado pelo IPHAN o Conjunto Arquitetônico da Praça Frei Caetano Brandão (Largo da Sé) - e, posteriormente, com as leis urbanísticas mais restritivas, houve uma desaceleração no processo de verticalização no $\mathrm{CHB}$, fazendo com que a incorporação imobiliária redirecionasse seus investimentos e ações para fora do Centro Histórico. Assim, bem antes do surgimento dos planos de desenvolvimento urbano de Belém, já havia certa preocupação em intervir no processo de demolição e descaracterização de edificações de valor histórico.

Os planos de caráter compreensivo somente surgiram em Belém a partir da década de 1970, sendo, desde então, elaborados diversos documentos de planejamento municipal e metropolitano com a finalidade de ordenamento territorial, os quais, de uma forma ou de outra, deram tratamento ao centro e, em especial, à sua área histórica, como se verá a seguir.

\section{Plano de Desenvolvimento da Grande Belém (PDGB)}

O Plano de Desenvolvimento da Grande Belém, instituído pela Lei n. ${ }^{\circ}$ 7.054, de 27 de dezembro de 1977, definiu a política de desenvolvimento urbano municipal e apresentou como escopo fundamental o controle e disciplinamento da expansão urbana. Esse plano estabeleceu objetivos e diretrizes a serem implantados, em níveis municipal e metropolitano, nas seguintes áreas de atuação: desenvolvimento econômico, desenvolvimento sociocultural, melhoria das condições de vida urbana e instrumentalização do processo de planejamento (BELÉM, 1975).

No diagnóstico apresentado, a urbanização, na escala metropolitana, era condicionada pelo problema da expansão urbana do Município de Belém, e este deveria ser equacionado pela reestruturação viária e pelo zoneamento. Com esse objetivo,
Figura 5 • Complexo Feliz Lusitânia Fonte: BToscano (2014). 
foram definidas como diretrizes principais a descentralização das funções básicas mediante a formação e o fortalecimento de subcentros, e o disciplinamento do uso do solo pela predominância de usos.

À área central de Belém foi atribuída a função de núcleo central metropolitano e, em determinadas situações, de centro regional. Para viabilizar essas condições, qualquer mudança no processo de crescimento da área metropolitana não deveria alterar o patrimônio cultural e histórico, entendidos como os elementos que conferiam caráter de identidade ao $\mathrm{CHB}$.

Vinculado ao eixo "Melhoria de condições de vida", o PDGB apresentou um estudo denominado "Remanejamento da área central", que objetivava criar condições necessárias ao desenvolvimento do Centro, considerando seu caráter de principal centralidade da cidade. Para isso propunha a ampliação das funções do CHB por meio do desenvolvimento de atividades de natureza cultural e turística. Previa também a melhoria do sistema de circulação de veículos e pedestres; a mudança de usos, com estímulo à implantação de equipamentos culturais e de lazer; a eliminação dos conflitos decorrentes das atividades portuárias; a recuperação e valorização dos espaços e edificações de valor histórico; e o estímulo à utilização da área no período noturno.

A proposta de zoneamento para a área central visou à preservação do patrimônio ambiental urbano, à valorização de sua paisagem urbana, à implantação de usos compatíveis com as funções centrais e com as características do conjunto histórico e artístico. Assim, foi definida a "Zona Comercial Central" (ZCC), para a qual foram propostas três subzonas: a primeira, de uso especial, na Cidade Velha, para preservação integral; a segunda, predominantemente comercial, mantendo o padrão de ocupação preponderante de uso comercial e de serviço, limitando o gabarito de altura até 3 (três pavimentos); e a terceira, de uso misto, na área periférica ao centro comercial com indícios de deterioração, permitindo coeficientes de ocupação mais elevados, objetivando a renovação urbana da área (BELÉM, 1977).

O PDGB, ao promover as propostas de expansão da ocupação urbana, teve o cuidado de estudar especificamente a área central, dando-lhe a devida importância como centro urbano principal e tradicional, primando por suas características de espaço com interesse à preservação, por representar o retrato de toda a história da ocupação da cidade desde sua fundação, abrigando a principal base econômica representada pelo comércio especialmente vinculado a condição de entreposto ribeirinho e principal polo de abastecimento metropolitano. Ao propor a descentralização de funções centrais, esse plano procurou reforçar o papel de primazia do $\mathrm{CHB}$ na hierarquia de centros proposta e dinamizá-lo com a inserção de novas atividades culturais e turísticas, a serem abrigadas, em especial, nos prédios históricos, reconhecendo, mesmo que implicitamente, o esvaziamento relativo que a descentralização proposta poderia promover.

Corrêa (1989) atribui ao caráter generalista, superficial e conflitante das proposições do PDGB as causas das dificuldades de assimilação destas pela sociedade e de suas viabilizações ope- 
racionais. Para esse autor, o arcabouço instrumental, restrito a mecanismos programáticos (programas e projetos setoriais) e normativos (legislação de uso e ocupação do solo) tradicionais revelam a fragilidade do PDGB, comum aos planos compreensivos urbanos brasileiros da época. Como consequência, os projetos propostos pelo plano, quando realizados, o foram de maneira isolada e aleatória.

\section{Plano de Estruturação Metropolitana (PEM)}

Elaborado em 1980 com abrangência até 1989, o Plano de Estruturação Metropolitana (PEM) foi caracterizado como instrumento que, juntamente com o Sistema Estadual de Planejamento (SEP), "viabilizaria a integração e a racionalização das ações planejadas no espaço metropolitano de Belém", então constituído pelos municípios de Belém e Ananindeua (PARÁ, 1992).

Segundo consta do documento, o PEM foi elaborado sob a orientação federal e buscava priorizar o ordenamento territorial das funções urbanas com base em um modelo de estruturação espacial que previa a conquista de um espaço mais amplo e descentralizado, contribuindo para o gradativo descongestionamento da área central de Belém. Para isso, tomou como base a distribuição espacial de empregos, de população e a estruturação viária básica, e concebeu um modelo denominado de "descentralização concentrada" de atividades terciárias. Esse modelo consistia na "geração de uma rede de centros hierarquizados, cuja distribuição espacial objetivava orientar a ocupação do território metropolitano pelas demais funções urbanas" (PARÁ, 1992, p. 30). Tal modelo não foi efetivado, observando-se, ao contrário, "um aumento acelerado da concentração terciária no núcleo central metropolitano e uma ocupação periférica desordenada e de baixa densidade" (CORRÊA, 1989, p. 305)

Pouco do que foi previsto no PEM foi efetivamente implementado, como mostra Corrêa (1989). As ações desenvolvidas pelo Poder Público no CHB acabaram sendo pontuais e mais voltadas à requalificação de alguns espaços, como o projeto Belocentro, de 1982, que consistiu na restauração de prédios e calçadões na Rua João Alfredo e Av. Portugal, com a retirada de camelôs do local, e o projeto de requalificação das feiras do Ver-o-Peso e do Açaí, incluindo a Ladeira do Castelo, de 1986 (LÔBO; CORRÊA; RIBEIRO, 2009) (FIG. 2).

Se, por um lado, o PEM não chegou a ser institucionalizado, por outro, criou uma base de informações que foi utilizada em projetos de parcelamento urbano metropolitano e para subsidiar a legislação urbanística formulada posteriormente. Como legado dos estudos do PEM, teve-se, por exemplo, a instituição da Lei n. ${ }^{\circ}$ 7.401, de 1988 (Lei de Desenvolvimento Urbano), que criou oficialmente o $\mathrm{CHB}$ e estabeleceu seus limites, que compreendiam as zonas de preservação. Essa lei remeteu para regulamentação específica a definição e a identificação do bem imóvel a ser considerado como de valor histórico e arquitetônico, e condicionou o desmembramento e remembramento de lotes à prévia anuência de órgãos competentes. 
Mais tarde, em 1990, o tombamento do CHB foi inserido no artigo 228 da Lei Orgânica do Município de Belém (BELÉM, 1990). Porém o reconhecimento em nível federal do $C H B$ aconteceu somente, com a Portaria n. ${ }^{\circ}$ 54, de 2012, do Ministério da Cultura (BRASIL, 2012).

\section{Plano Diretor do Município de Belém (PDMB) de 1993}

O Plano Diretor do Município de Belém, instituído pela Lei n. ${ }^{\circ}$ 7.603, de 1993, afirmava ser fundamental considerar, na organização dos espaços do território municipal, "a preservação, a valorização e a difusão do patrimônio cultural, artístico e histórico do município; e a integração dos sistemas de transporte público aos objetivos da política de uso e ocupação do solo municipal e metropolitano" (art. $2^{\circ}, I X$ ), já que o sistema de circulação foi considerado o principal fator estruturante do espaço urbano.

O PDMB reconheceu haver uma intensa concentração de atividades no $\mathrm{CHB}$ e previu uma rede estrutural de transporte coletivo e outra para o tráfego geral, as quais deveriam "propiciar ligações diretas e de maior capacidade entre os subcentros, favorecendo a polinucleação, e atenuando a excessiva concentração exercida pelo centro histórico" (art. 65). Para ele, a estrutura urbana futura deveria considerar não apenas a expansão do centro, mas a formação de subcentros localizados no entroncamento da Avenida Almirante Barroso com a Rodovia Augusto Montenegro e em pontos estratégicos localizados na própria Rodovia Augusto Montenegro e no Distrito de Icoaraci (BELÉM, 1993).

Observa-se aqui, novamente, a presença de uma diretriz de descentralização das atividades no núcleo urbano tradicional, por meio da criação de subcentros expandidos. Essa estratégia fundamentava-se na necessidade de equacionar os seguintes problemas identificados no centro: adensamento de atividades, congestionamento nas vias, saturação da infraestrutura, deterioração ou inadequação das edificações às novas necessidades do mercado.

O Plano Diretor do Município de Belém de 1993 ratificou o zoneamento da área do Centro Histórico e seu entorno estabelecido na Lei n 7.401 de 1988 (Lei de Desenvolvimento Urbano), bem como formulou diretrizes de políticas setoriais a serem consideradas em posterior regulamentação da área.

Diante da intensificação dos problemas de degradação e descaracterização física da área do $\mathrm{CHB}$, foi instituída a Lei n. ${ }^{\circ}$ 7.709, de 1994, que regulamentou o uso e a ocupação do solo nesse espaço. Dessa lei constam, dentre outros, os parâmetros urbanísticos e as limitações edilícias para a área, o tombamento de diversos imóveis e a relação dos incentivos fiscais concedidos como estímulo à preservação dos imóveis tombados e de interesse à preservação.

Ressalte-se que várias tentativas foram feitas pelos setores ligados à construção civil, no sentido de aumentar os índices 
construtivos e gabaritos máximos permitidos no $\mathrm{CHB}$. Apesar dos esforços de técnicos da Prefeitura e dos movimentos sociais, duas alterações referentes ao aumento de gabarito de altura em espaços pontuais do centro foram aprovadas pela Câmara Municipal de Belém, visando à construção de grandes empreendimentos: a primeira, na Lei . $^{\circ} 8.448$, de 2005; e a segunda, na Lei n. ${ }^{\circ}$ 8.453, de 2005.

A normatização do CHB não foi acompanhada de ação institucional de caráter mais globalizante. As intervenções voltadas à preservação e, ao mesmo tempo, à dinamização econômica do CHB ficaram mais por conta das políticas estaduais e nacionais de preservação e da oferta de recursos federais. Tais ações se deram de forma fragmentada, explorando sobretudo alguns dos atributos histórico-culturais do CHB.

Data dos anos 1990 e 2000, por exemplo, as obras do Projeto Feliz Lusitânia, do complexo Estação das Docas, e as reformas do complexo Ver-o-Peso e da Feira do Açaí (FIG. 2). Pouco articuladas com as atividades desenvolvidas no seu entorno, à exceção das melhorias introduzidas na Feira do Ver-o-Peso, em 2002, tais intervenções não foram suficientes para evitar os processos de ocupação dos espaços públicos por atividades econômicas informais, degradação de edificações e infraestrutura urbana, e agravamento das condições de acessibilidade e mobilidade urbanas.

O processo de descentralização, por seu turno, acabou se operando pela atuação das forças do mercado, diante do crescimento periférico da malha urbana e do agravamento dos problemas de mobilidade.

\section{Plano Diretor do Município de Belém (PDMB) de 2008}

O Plano Diretor do Município de Belém passou por um processo de revisão, dando origem à Lei n. ${ }^{\circ} 8.655$, de 30 de julho de 2008. Nesse Plano, a estruturação espacial do Município considerou a distribuição das centralidades terciárias como forma de potencializar a formação de novos polos de comércio e serviços na cidade.

Quanto ao ordenamento territorial, propôs descentralizar as atividades terciárias, requalificar e dinamizar as centralidades secundárias e os corredores de atividades múltiplas. Ao mesmo tempo, deu como diretrizes preservar, legalizar, recuperar e manter as áreas de interesse histórico.

A preservação do patrimônio histórico e cultural veio expressa como um dos princípios fundamentais do Plano, que trouxe como um dos objetivos da política urbana municipal manter e ampliar os programas de preservação do patrimônio construído.

As diretrizes voltadas para o Centro Histórico de Belém se acham expressas em várias políticas setoriais, como a diretriz de dinamização e reabilitação socioeconômica, cultural e turística, na política de desenvolvimento econômico e a indicação à elaboração do plano de reabilitação e conservação de áreas de interesse à preservação do patrimônio histórico e cultural, na Política de Patrimônio Cultural (BELÉM, 2008). 
Especificamente para o $\mathrm{CHB}$, foram apontados objetivos e diretrizes no sentido de requalificar, preservar, conservar e reabilitar o núcleo histórico; estimular o uso habitacional; potencializar as atividades de turismo e negócios afins; melhorar as condições de mobilidade e acessibilidade na área; controlar o processo de adensamento construtivo e de implantação de empreendimentos potencialmente geradores de tráfego.

Quanto ao zoneamento para o $\mathrm{CHB},{ }^{7}$ com a nova lei, mudou-se a nomenclatura das zonas, mantendo-se o perímetro do sítio tombado e regulamentado pela Lei $n^{\circ}$ 7.709, de 1994 (FIG. 6). Contudo a setorização interna do CHB foi alterada, considerando-se os atributos históricos, paisagísticos e culturais; as funções como centro tradicional comercial, administrativo, de serviços e portuário; nível de degradação dos imóveis históricos; e a intensidade de ocupação.
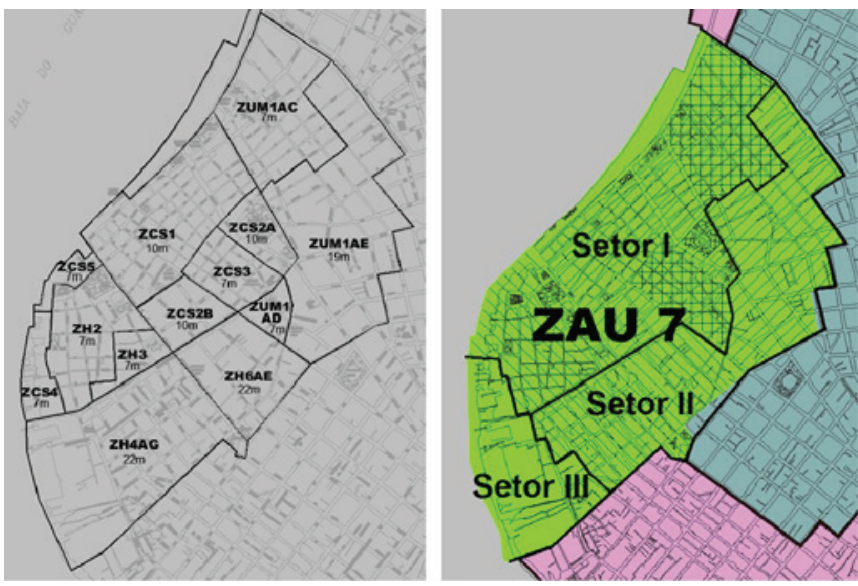

Percebe-se, nesse plano, não só a reafirmação da necessidade de continuar o processo de descentralização das atividades terciárias para os subcentros já em consolidação, mas também uma intenção de recuperar o CHB, tanto em relação a sua dinâmica habitacional, em especial na área comercial onde o uso majoritário é o não habitacional, quanto no tocante à recuperação de sua infraestrutura e edificações, e das atividades econômicas e culturais, otimizando os usos e valorizando o patrimônio arquitetônico e cultural.

Um balanço preliminar das ações previstas no plano que foram efetivadas é bastante desfavorável. O plano do Centro Histórico não foi elaborado. A promoção de ações voltadas para a ocupação de edificações subutilizadas ou desocupadas não se efetivou, assim como permaneceram sem regulamentação os instrumentos que poderiam colaborar para a redução de imóveis ociosos no $\mathrm{CHB}$.

As ações no CHB permaneceram sendo pontuais e voltadas, sobretudo, para a manutenção emergencial de alguns espaços públicos, como a Feira do Ver-o-Peso, e para as recuperações de alguns imóveis relevantes, estas financiadas com recursos do Programa de Aceleração do Crescimento (PAC/Centro Histórico).

Afora isso, destaca-se a Portaria n. ${ }^{\circ}$ 54, de 8 de maio de 2012, pela qual o tombamento do conjunto arquitetônico, urbanístico
7. Vale ressaltar que, nos zoneamentos existentes nas referidas leis, estão o Centro Histórico tombado e a sua respectiva área de entorno, conforme estão dispostos na Lei n. ${ }^{\circ} 7.709$, de 1994.

Figura $6 \bullet$ Zonas do Centro Histórico de Belém

Fonte: Belém (1994; 2008). 
e paisagístico dos bairros da Cidade Velha e Campina foi homologado pelo IPHAN.

\section{Considerações finais}

A área delimitada e tombada como Centro Histórico de Belém, além de representar um valioso patrimônio material, configura-se na principal centralidade urbana e metropolitana, apresentando grande concentração de empregos, de estabelecimentos de comércio e serviços e de instituições públicas. Sua posição estratégica na Região Amazônica proporciona, ainda hoje, a atração de expressivos fluxos de pessoas e mercadorias procedentes, não somente da área metropolitana como também de outros municípios ribeirinhos que se acham sob a área de influência de Belém. Esses aspectos foram quantificados e reconhecidos nos documentos de planejamento analisados.

Em todos os planos de ordenamento territorial elaborados a partir da década de 1970, o CHB recebeu tratamento destacado, sendo prevista como diretriz a descentralização das atividades de comércio e serviços, mediante o estabelecimento e fomento de núcleos secundários na área de expansão. Esperava-se, com essa estratégia, descongestionar o Centro e, ao mesmo tempo, permitir sua recuperação e preservação.

Concomitantemente, tais documentos vêm estabelecendo uma série de diretrizes e instrumentos indutores para que a preservação do $\mathrm{CHB}$ seja garantida. A recuperação e a manutenção do patrimônio edificado, a implantação de atividades econômicas específicas e o fomento ao uso residencial têm sido propostos como forma de promover a ocupação das edificações subutilizadas, desocupadas ou abandonadas, diminuindo assim o grau de degradação presente na área. Nesse sentido, os planos vêm incorporando as orientações de documentos nacionais e internacionais destinados à preservação do patrimônio cultural, inclusive assumindo o tombamento e outros instrumentos de preservação previstos por meio de legislações.

Os planos, contudo, não aprofundaram o debate sobre as novas funções que esse Centro deveria desempenhar, no sentido inclusive de avaliar a viabilidade e a sustentabilidade econômica das atividades para ele propostas.

Do estabelecido nos planos elaborados para Belém pouco foi implementado, contribuindo, assim, para que alguns dos problemas apresentados no Centro permaneçam comprometendo a manutenção do patrimônio histórico a ser preservado. Tais problemas somente não assumem maior gravidade porque há a permanência de muitas atividades de comércio e serviços tradicionais e populares no centro histórico; as restrições impostas pela legislação urbanística de preservação do patrimônio; e a mobilização da sociedade civil, que vem impedindo processos de derrubada de imóveis e contendo as iniciativas de liberação da verticalização, mesmo sem garantir a integridade e a conservação de muitos dos prédios de interesse histórico existentes na área. 


\section{Referências}

A ESTAÇÃO. Estação das Docas: Pará 2000, Belém. Disponível em: <http://www.estacaodasdocas.com.br/institucional/ sobre/>. Acesso em: 22 jan. 2015.

BELÉM (Município). Lei n. 7.054, de 27 de dezembro de 1977. Plano de desenvolvimento da Grande Belém. v. 1, tomo 2. Belém: CODEM, 1977.

BELÉM (Município). Lei n. 7.401, de 29 de janeiro de 1988. Dispõe sobre a política municipal de desenvolvimento urbano, de acordo com as diretrizes de estruturação espacial da Região Metropolitana de Belém (RMB). Belém: Câmara Municipal, 1988. Disponível em: <http://cm-belem.jusbrasil.com.br/ legislacao/588919/lei-7401-88 >. Acesso em: 2 ago. 2013.

BELÉM (Município). Lei n. 7.603, de 13 de janeiro de 1993. Dispõe sobre o Plano Diretor do Município de Belém e dá outras providências. Belém: Câmara Municipal, 1993. Disponível em: <http://cm-belem.jusbrasil.com.br/legislacao/585164/lei-760393>. Acesso em: 20 jul. 2013.

BELÉM (Município). Lei n. 7.709, de 18 de maio de 1994. Dispõe sobre a preservação e proteção do patrimônio histórico, artístico, ambiental e cultural do Município de Belém e dá outras providências. Belém: Câmara Municipal, 1994. Disponível em: <http://cm-belem.jusbrasil.com.br/legislacao/583044/lei7709-94>. Acesso em: 25 jul. 2013.

BELÉM (Município). Lei n. 8.448, de 6 de setembro de 2005. Altera os anexos III e IV B da Lei n. 7.709, de 18 de maio de 1994, que dispõe sobre a Preservação e Proteção do Patrimônio Artístico, Ambiental e Cultural do Município de Belém, e dá outras providencias. DOM, Belém, n. 10.527, $2^{\circ}$ caderno, 21 out. 2005a.

BELÉM (Município). Lei n. 8.453, de 3 de outubro de 2005. Adita art. $50 \mathrm{~A}$ e altera os anexos III e IV B da Lei n. 7.709, de 18 de maio de 1994, que dispõe sobre a Preservação e Proteção do Patrimônio Artístico, Ambiental e Cultural do Município de Belém, e dá outras providências. DOM, Belém, n. 10.527, de 21 out. 2005b.

BELÉM (Município). Lei n. 8.655, de 30 de julho de 2008. Dispõe sobre o Plano Diretor do Município de Belém e dá outras providências. Belém: Câmara Municipal, 2008. Disponível em: <http://www.belem.pa.gov.br/planodiretor/Plano_diretor_atual/ Lei_N8655-08_plano_diretor.pdf>. Acesso em: 10 set. 2013.

BELÉM (Município). Lei Orgânica do Município de Belém, de 30 de março de 1990. Belém: Câmara Municipal, 1990. Disponível em: <http://www.belem.pa.gov.br/semaj/app/paginas/ lom.html>. Acesso em: 2 ago. 2013.

BRASIL. Decreto-Lei n. 25, de 30 de novembro de 1937. Organiza a proteção do patrimônio histórico e artístico nacional. Portal da Legislação, Brasília, Presidência da República. Disponível em: <http://www.planalto.gov.br/CCiVil_03/Decreto-Lei/Del0025.htm >. Acesso em: 6 abr. 2014.

BRASIL. Ministério da Cultura. "Cartas Patrimoniais": Carta de Atenas, 1933. Brasília: IPHAN, 2000a. (Cadernos de Docu- 
mentos, 3). Disponível em: <http://portal.iphan.gov.br/portal/ baixaFcdAnexo.do?id=257> . Acesso em: 28 maio 2014.

BRASIL. Ministério da Cultura. "Cartas Patrimoniais": Carta de Petrópolis. Brasília: IPHAN, 2000b. (Cadernos de Documentos, 3). Disponível em: <http://portal.iphan.gov.br/portal/ baixaFcdAnexo.do?id=257> . Acesso em: 28 maio 2014.

BRASIL. Ministério da Cultura. Portaria n. 54, de 8 de maio de 2012. Homologa o tombamento do Conjunto Arquitetônico e Paisagístico dos Bairros da Cidade Velha e Campina no Município de Belém, no Estado do Pará. Brasília: Ministério da Cultura, 2012. Disponível em: <http://www.jusbrasil.com. br/diarios/36832518/dou-secao-1-10-05-2012-pg-15>. Acesso em: 10 ago. 2014.

BTOSCANO. Complexo Feliz Lusitânia. 2011. Disponível em: <http://www.panoramio.com/photo/51797639. Acesso em: 22 mar. 2014.

CARTA de Atenas: 1931. Cadernos de Sociomuseologia, Lisboa, Universidade Lusófona de Humanidades e Tecnologias, n. 15, p. 83-89, 1999. Disponível em: <http://revistas.ulusofona. pt/index.php/cadernosociomuseologia/article/view/332/241 >. Acesso em: 5 jan. 2014.

CORRÊA, Antônio José Lamarão. O espaço das ilusões: planos compreensivos e planejamento urbano na Região Metropolitana de Belém. 1989. 339 f. Dissertação (Mestrado em Planejamento de Desenvolvimento) - Núcleo de Altos Estudos Amazônicos, Universidade Federal do Pará, Belém.

ICOMOS. Carta de Washington: 1986. Cadernos de Sociomuseologia, Lisboa, Universidade Lusófona de Humanidades e Tecnologias, n. 15, p. 227-231, 1999. Disponível em: <http:// revistas.ulusofona.pt/index.php/cadernosociomuseologia/article/view/343/252 > . Acesso em: 22 out. 2014.

LEFEBVRE, Henri. A revolução urbana. Belo Horizonte: Editora UFMG, 2002.

LEFEBVRE, Henri. O direito à cidade. São Paulo: Moraes, 1991.

LÔBO, Marco Aurélio Arbage (coord.); CORRÊA, Antônio José Lamarão; RIBEIRO, Paulo de Castro. Oferta e demanda habitacional no Centro Histórico de Belém. Belém: Companhia de Habitação do Estado do Pará - COHAB, 2009.

MERCÊS, Simaia do S. S. das; TOURINHO, Helena L. Z.; LÔBO, Marco A. A. Locação social no Centro Histórico de Belém: investigação introdutória. Caderno $\mathrm{CRH}$, Salvador, v. 27, n. 71, p. 299-311, maio/ago. 2014.

PARÁ. Lei n. 5.778, de 15 de dezembro de 1993. Define os limites político-administrativos e territoriais entre os municípios de Belém e Ananindeua e dá outras providências. Diário Oficial do Estado, Belém, n. 27.615, 16 dez. 1993.

PARÁ. Plano de Estruturação Metropolitana (PEM): reavaliação. Belém: Seplan, 1992.

PARAONLINE. Teatro infantil alegra e educa na Estação das

Docas. 2013. Disponível em: http://www.paraonline.com.br/ 
teatro-infantil-alegra-e-educa-na-estacao-das-docas/. Acesso em: 11 jan. 2014.

PENTEADO, Antônio Rocha. Belém: estudo de geografia urbana. Belém: Editora UFPA, 1968.

SARGES, Maria de Nazaré. Belém: riquezas produzindo a Belle-Époque 1870-1912. Belém: Paka-Tatu, 2002.

SEBASTIÃO, Ana Sofia C. Planejamento estratégico para o Centro Histórico de Torres Vedras. 2010. 145 f. Dissertação (Mestrado em Gestão do Território e Urbanismo) - Instituto de Geografia e Ordenamento do Território, Universidade de Lisboa, Lisboa囚. Disponível em: <http://hdl.handle. net/10451/3862 >. Acesso em: 16 dez. 2013.

TOURINHO, Andréa de Oliveira. Do centro às novas centralidades: uma trajetória de permanências terminológicas e rupturas conceituais. In: GITAHY, Maria Lúcia; LIRA, José Tavares Correia de. (Org.). Cidade: impasses e perspectivas. São Paulo: FAU: Annablume; FUPAM, 2007, p. 11-28. (Coleção Arquiteses, v. 2).

UNESCO. Carta de Nairóbi: 1976. Cadernos de Sociomuseologia, Lisboa, Universidade Lusófona de Humanidades e Tecnologias, n. 15, p. 187-208, 1999a. Disponível em: <http:// revistas.ulusofona.pt/index.php/cadernosociomuseologia/article/view/339/248>. Acesso em: 5 jan. 2014.

UNESCO. Carta de Veneza: 1994. Cadernos de Sociomuseologia, Lisboa, Universidade Lusófona de Humanidades e Tecnologias, n. 15, p. 105-110, 1999b. Disponível em: <http:// revistas.ulusofona.pt/index.php/cadernosociomuseologia/article/view/334/243 >. Acesso em: 5 jan. 2014.

VILLAÇA, Flávio. O espaço intraurbano no Brasil. São Paulo: Studio Nobel, 2001.

VILLAÇA, Flávio. Reflexão sobre as cidades brasileiras. São Paulo: Studio Nobel, 2012.

VILLASCHI, Juca. O patrimônio cultural brasileiro. In: VILLASCHI, Juca. Cidade. Ouro Preto: FAOP, 2008, p. 27. (Cadernos de Ofícios, 2).

WIKILICIAS. Uma maneira de conhecer Belém, a capital do Pará, é visitar o Mercado Ver-o-Peso. 2014. Disponível em: http://wikilicias.com.br/2014/02/28/belem-pa-brasil/. Acesso em: 20 de jun. 2015.

Recebido em 10/02/2015

Aprovado em 06/04/2015 